\title{
Nitrobenzene along with Organophosphorous Compound Poisoning
}

\author{
${ }^{1}$ Veeresh Hosur, ${ }^{2} \mathrm{GS}$ Karthik, ${ }^{3} \mathrm{~S}$ Rangalakshmi, ${ }^{4} \mathrm{H}$ Sahajananda
}

\begin{abstract}
Major cause of premature mortality globally and 113,914 suicides are recorded annually from India. Variety of chemicals have been used. Nitrobenzene is used as a pesticide. Here, we report a case of acute poisoning with nitrobenzene which is an organic compound, where clinical evaluation and timely management, helped to save a life.
\end{abstract}

Keywords: Acute methemoglobinemia, Atropine, Intermediate syndrome, Methylene blue, Nitrobenzene poisoning, Organophosphorous poison, Pralidoxime.

How to cite this article: Hosur V, Karthik GS, Rangalakshmi S, Sahajananda H. Nitrobenzene along with Organophosphorous Compound Poisoning. J Med Sci 2016;2(3):56-58.

\section{Source of support: Nil}

Conflict of interest: None

\section{INTRODUCTION}

Among aromatic organic compounds, nitrobenzene is used in making dyes and paints. It is also used in both printing technology and manufacture of lubricating oil and synthetic rubber. In India, 20\% nitrobenzene emulsion is widely used as a pesticide. Different studies ${ }^{1-3}$ have mentioned nitrobenzene lethal dose as 1 to $10 \mathrm{gm}$. Nitrobenzene ingestion primarily induces methemoglobinemia. The toxic dose resulting in methemoglobinemia was estimated in one case study at 4.3 to $11 \mathrm{gm}$ based on urinary p-nitrophenol levels. ${ }^{4}$

\section{CASE REPORT}

A 60 -year-old male consumed $300 \mathrm{~mL}$ of a mixture of $40 \%$ profenofos with cypermethrine $4 \%$ organophosphorus compounds and nitrobenzene $20 \%$ along with alcohol. He was brought to the casualty in an irritable, drowsy state and looked cyanosed, but was arousable and tried to follow simple commands. Pupils were constricted and nonreactive. Obstructed labored breathing with a respiratory rate

\footnotetext{
${ }^{1}$ Resident, ${ }^{2}$ Associate Professor, ${ }^{3}$ Professor, ${ }^{4}$ Professor and Head

${ }^{1-4}$ Department of Anaesthesiology, RajaRajeswari Medical College \& Hospital, Bengaluru, Karnataka, India

Corresponding Author: Veeresh Hosur, Resident, Department of Anaesthesiology, RajaRajeswari Medical College \& Hospital, Bengaluru, Karnataka, India, Phone: +919164517578 e-mail: veeresh.hosur@gmail.com
}

of around 25 breaths/minute and bilateral crepitations were heard on auscultation. Pulse rate was 60/minute, blood pressure 190/100 $\mathrm{mm} \mathrm{Hg}$ and oxygen saturation of $\left(\mathrm{SpO}_{2}\right)$ of $80 \%$ on room air. In view of progressive deterioration of Glasgow coma scale and saturation, patient was intubated with a no. 8 cuffed oral endo tracheal tube. Patient was put on synchronized intermittent mandatory ventilation (SIMV) volume controlled (VC) with pressure support (PS) mode of ventilation with $\mathrm{FiO}_{2}$ of 1 , respiratory rate of 16, tidal volume of $400 \mathrm{~mL}$, positive end-expiratory pressure of $5 \mathrm{~cm}$ of $\mathrm{H}_{2} \mathrm{O}$, with a pressure support of $16 \mathrm{~cm}$ of $\mathrm{H}_{2} \mathrm{O}$ and was shifted to medical intensive care unit (MICU). Blood samples drawn for arterial blood gas (ABG) had a chocolate brown appearance and had a $\mathrm{pH}$ of 7.27, $\mathrm{PCO}_{2}$ of $39 \mathrm{~mm} \mathrm{Hg}, \mathrm{PO}_{2}$ of $50 \mathrm{~mm} \mathrm{Hg}, \mathrm{HCO}_{3}$ of $17 \mathrm{mEq} / \mathrm{L}$, and $\mathrm{SpO}_{2} 85 \%$. Diagnosis of organophosphorous (OP) poisoning with nitrobenzene poisoning causing methemoglobenemia was made and was treated with injection methylene blue 1\%, $50 \mathrm{mg}$ 6th hourly, atropine infusion was started at $5 \mathrm{mg} /$ hour and adjusted to maintain heart rate between 80 and 120 beats/minute. Slow intravenous (IV) infusion of $1 \mathrm{gm}$ of ascorbic acid in 5\% dextrose 8 th hourly was also administered. Pralidoxime $2 \mathrm{gm}$ IV bolus, followed by $1 \mathrm{gm}$ IV 6th hourly was administered, along with the broad spectrum antibiotic.

The right side internal jugular vein was cannulated with a triple lumen central venous catheter to maintain normal central venous pressure. Hydration was achieved with crystalloids. Urine output was maintained above $100 \mathrm{~mL} /$ hour with IV furosemide. On investigation, hemoglobin $(\mathrm{Hb})$ was $10 \mathrm{gm} \%$ and other blood parameters were within normal range. Intravenous methylene blue improved $\mathrm{SpO}_{2}$ to $97 \%$ over the next 30 minutes, only to return to $85 \%$ in the next 3 hours, with a similar response to another dose. Two units of fresh blood were transfused which improved the $\mathrm{SpO}_{2}$ to 92 to $94 \%$. On day 5, patient was conscious, on invasive ventilation, vital signs: Temperature was $100^{\circ} \mathrm{F}$, pulse rate was 116 beats/minute, pupils were dilated and sluggish, twitchings were also present. Parenteral nutrition was started. Patient gradually developed OP intermediate syndrome. The dose of atropine was adjusted to $2 \mathrm{mg} /$ hour and prallidoxime $500 \mathrm{mg}$ was administered. On day 8 , patient was tracheostomized in view of waxing and waning symptoms of OP poisoning. He was put on SIMV mode 
with trials of continuous positive airway pressure to wean the patient off ventilator. Methylene blue was stopped in view of improved $\mathrm{SpO}_{2}(94-100 \%)$ with $\mathrm{FiO}_{2}$ of $0.4 \%$.

By day 16, patient was maintaining $\mathrm{SpO}_{2}$ of 94 to $100 \%$ on room air and was mobile and taking oral feeds. Atropine was tapered off and stopped. Blood investigations and other parameters returned to normal range. On day 17 (Fig. 1), patient was decannulated and stoma was closed with sterile gauze dressing and patient was able to vocalize and maintain $\mathrm{SpO}_{2}$ of $>90 \%$ on room air without much change in vital parameters and was on close observation. On 21st day, post-admission to MICU, patient was shifted to step-down intensive care unit which was uneventful and was discharged home on 28th day with supplemental iron, folate, ascorbic acid, and liver enzyme. He was advised incentive spirometry and other breathing exercise techniques.

\section{DISCUSSION}

Methemoglobinemia is a condition in which the ferrous $\left(\mathrm{Fe}^{2+}\right)$ state of iron within $\mathrm{Hb}$ gets oxidized to ferric $\left(\mathrm{Fe}^{3+}\right)$ state, which results in the inability to transport oxygen and chocolate brown discoloration of blood. ${ }^{5}$ Two different mechanisms result in producing low level of methemoglobin. In hexose-monophosphate shunt pathway, the erythrocyte reduces oxidizing agents by glutathione before leading to formation of methemoglobin. In the second mechanism utilization of diaphorase-I and diaphorase-II enzyme systems with the help of nicotinamide adenine dinucleotide dehydrogenase (NADH) and nicotinamide adenine dinucleotide phosphate reduced (NADPH) enzymes respectively reduce methemoglobin to its $\mathrm{Fe}^{2+}$ state. The cytochrome b5 reductase enzyme catalyses the NADH-dependent reaction. ${ }^{6,7}$

Acute intoxication is usually asymptomatic up to methemoglobin level of 10 to $15 \%$. There will be only

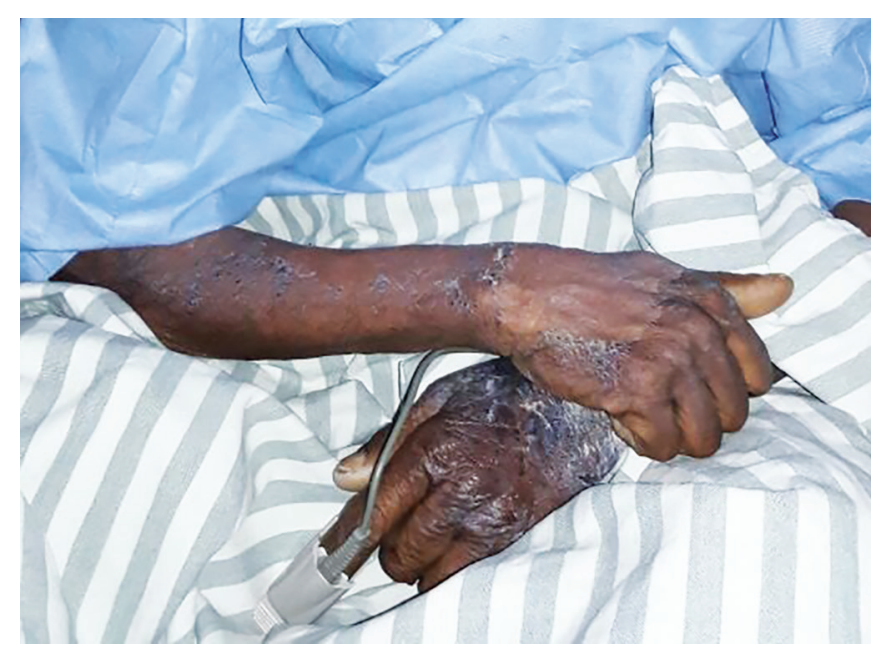

Fig. 1: Patient on day 17 after decannulation cyanosis. When it exceeds $20 \%$, it leads to multiple signs and symptoms including headache, breathlessness, chest pain, increased respirations, and tachycardia. When it reaches 40 to 50\%, confusion, lethargy, and metabolic acidosis occur which will ultimately lead on to seizures, bradycardia, ventricular dysrythmia, hypertension, and coma. The levels around $70 \%$ are fatal. Patients with anemia or glucose-6-phosphate dehydrogenase (G6PD) deficiency will develop more severe symptoms of poisioning. ${ }^{7,8}$ Leukocytosis has been reported, with relative lymphopenia. ${ }^{1}$

It also causes hepatosplenomegaly, elevated liver enzymes, and hemolytic anemia. Tools of diagnosis include distinguishing smell of bitter almonds, persevering cyanosis on continuous hyperbaric oxygen therapy without preexisting cardiopulmonary disease, minimal arterial oxygen saturation, and atypical ABG analysis. In this poisoning, arterial blood turns into chocolate-brown color and it fails to turn bright red on shaking of the blood sample, which is the characteristic feature of methemoglobinemia. Presence of nitrobenzene ${ }^{6,7,9}$ can be detected by pulse oximetry, CO-oximetry, Evelyn Malloy method and enzyme assay using spectrophotometric techniques. Methemoglobinemia can be congenital or acquired; methylene blue, 1 to $2 \mathrm{mg} / \mathrm{kg}$ is administered as a $1 \%$ solution IV over 3 to 5 minutes, repeated at $1 \mathrm{mg} / \mathrm{kg}$ in 1 hour as necessary. This drug is the antidote of choice for acquired (toxic) methemoglobinemia to control fluctuating symptoms. Methylene blue can also cause false $\mathrm{SpO}_{2}$ levels. This antidote is toxic at doses more than $7 \mathrm{mg} / \mathrm{kg}$ and can cause breathlessness, chest pain, and hemolysis. ${ }^{6,10,11}$ Methylene blue is an external cofactor and it donates electrons which rapidly reduces methemoglobin to $\mathrm{Fe}^{2+}$ state through NADPH-dependent methemoglobin reductase system. Methylene blue is contraindicated in patients with G6PD deficiency. It can cause severe hemolysis and it can swap its action causing methemoglobinemia at higher doses. Methylene blue is also used in the treatment of urolithiasis, cystitis, herpes simplex infection. It is also antidote of choice in cyanide poisoning. ${ }^{2,6,7}$

Methylene blue in repeated low doses helped in tiding over the fluctuating symptoms due to the release of nitrobenzene from the body stores. This also helped us in not exceeding the toxic dose of the antidote. The oxygen carrying capacity was improved by fresh blood transfusion and increased $\mathrm{Hb}$ content which in turn improved the patient symptomatically. Taking care of nutrition, adequate urine output, and hepatoprotection prevented renal and liver failure, which have been cited as late effects. ${ }^{712}$ Forced diuresis led to a rapid fall in methemoglobin levels and improved discoloration. ${ }^{1}$ Ascorbic acid supplements are useful for follow-up management of methemoglobinemia. ${ }^{13}$ 


\section{CONCLUSION}

Treatment of poisoning caused by a mixture of compounds is a challenging situation and becomes grave when the patient does not respond properly to treatment. Acute methemoglobinemia is usually associated with high mortality; hence, an early aggressive management of poisoning should be attempted., ${ }^{910}$ Main drugs used in the treatment are methylene blue and ascorbic acid. Red blood cells exchange transfusion and hyperbaric oxygen therapy are usually reserved for patients who are resistant to standard treatment.

Treatment for OP compound included atropine (antimuscarinic agent) and prallidoxime (enzyme reactivator). Dose of atropine mainly depends on signs and symptoms of patient. Dose adjustment of atropine plays a vital role in the treatment. ${ }^{14,15}$

\section{REFERENCES}

1. International Programme on Chemical Safety (IPCS) 2003(8.11) Nitrobenzene. Environmental health criteria 230, Geneva: WHO; 2003. Available from: http://www.inchem. org/documents/ehc/ehc/ehc230.htm\#8.1.1;\#7.8

2. Toxicological Review of Nitrobenzene, Integrated Risk Information System (IRIS); March 2007.

3. Chongtham DS, Phurailatpam J, Singh MM, Singh TR. Methaemoglobinemia in nitrobenzene poisoning. J Postgrad Med 1997 Jul-Sep;43(3):73-74.

4. Agency for Toxic Substances and Disease Registry (ATSDR). Toxicological profile for nitrobenzene. US Department of Health and Human Services, Public Health Service. Atlanta, GA; 1990.

5. Michelle, Kumar M. Methemoglobinemia overview eMedicine from Web med. [Online] Available from: http://www. emedicine.medscape.com/ article/956528-overview. [Accessed June 2012].

6. Gupta G, Poddar B, Salaria M, Parmar V. Acute nitrobenzene poisoning. Indian Pediatr. 2000 Oct;37(10):1147-1148.

7. Dutta R, Dube SK, Mishra LD, Singh AP. Acute methemoglobinemia. Internet $\mathrm{J}$ Emerg Intensive Care Med. 2008;11:1092-4051.

8. Chongtham DS, Phurailatpam J, Singh MM, Singh TR. Methemglobinemia in nitrobenzene poisoning. J Postgrad Med. 1997 Jul-Sep;43(3):7374.

9. Martínez MA, Ballesteros S, Almarza E, Sánchez de la Torre C, Búa S. Acute nitrobenzene poisoning with severe associated methemoglobinemia: identification in whole blood by GC-FID and GC-MS. J Anal Toxicol. 2003 May-Jun;27(4): 221-225.

10. Patel AB, Dewan A, Upadhyay KJ, Patel SA, Patel JK. Chemically induced methemoglobinemia from acute nitrobenzene poisoning. The Internet J Lab Med. 2009;3(2): 34-37.

11. Schellek MS, Ungek RJ, Kelnek MJ. Effects of intravenously administered dyes on pulse oximetry readings. Anesthesiology. 1986 Nov;65(5):550-551.

12. Wakefield JC. Nitrobenzene toxicological overview. Health Protection Agency. p 1-10 [last accessed in 2008] [7]. Available from: http://www.hpa.org.uk/web/HPAwebFile/ HPAweb_C/1222068850334

13. Kaushik P, Zuckerman SJ, Campo NJ, Banda VR, Hayes SD, Kaushik R. Celecoxib-Induced Methemoglobinemia. Ann Pharmacother. 2004;38:1635-1638.

14. Tripathi KD. Essentials of Medical Pharmacology, 6th edition. New Delhi: Jaypee Brothers Medical Publishers (P) Ltd.; 2010. p. 93-95.

15. Shafferman A, Ordentlich A, Barak D, Stein D, Ariel N, Velan B. Aging of phosphylated human acetylcholinesterase: catalytic processes mediated by aromatic and polar residues of the active centre. Biochem J 1996 Sep 15;318(Pt 3): 833-840. 